\title{
EDITORIAL
}

\section{Detecting "occult" viral infection after marrow transplantation}

\author{
S.W. Crawford
}

In this issue of the Journal, BARBERÁ et al. [1] report on the detection of previously unsuspected Cytomegalovirus (CMV) pulmonary infection in the lungs of marrow transplant recipients who died with evidence of diffuse alveolar damage [1]. Detection of such "occult" infections is of great importance and would have major implications for the care of marrow recipients. Viral pneumonia has been the leading infectious cause of death following marrow transplantation, and CMV assumed the role of "the Captain of Death" among the viruses. Sixty percent of diffuse pneumonias have been due to CMV [2]. For the period between 30 and 150 days after transplantation, this rate is increased to $80 \%$ [3]. Other herpes group viruses, such as herpes simplex virus (HSV) and varicella zoster virus (VZV), have been less commonly seen because of the prophylactic administration of acyclovir.

To place this paper in perspective, it is important to understand the pathogenesis of CMV pneumonia after marrow transplantation. The incidence of CMV pneumonia has varied according to various epidemiological features of the patient. The major factor is the patient's previous experience with CMV infection as evidenced by the pretransplant serology. Among seropositive patients (who presumably carry latent virus), an incidence of CMV infection (defined as excretion of virus) of approximately $75 \%$ and an incidence of CMV pneumonia as high as $25 \%$ have been reported [2]. The incidence both of infection and pneumonia among seropositive patients seem unaffected by marrow donor serology or by transfusion practices. It is presumed that most, if not all, CMV infection occurring in seropositive patients is due to reactivation of latent virus during periods of reduced CMVspecific CD8+ cytotoxic T-lymphocyte (CTL) activity $[2,4,5]$.

In seronegative patients with seronegative marrow donors, the risk of infection is entirely attributable to blood product exposure, and a 30-40\% incidence of primary infection has been observed. The incidence of CMV pneumonia among seronegative patients has been $10 \%$ or less. These risks can be eliminated by use of screened seronegative or filtered blood products [6].

Other factors also affect the risk of CMV pneumonia. The most prominent of these is the occurrence of acute graft-versus-host disease (GVHD) among allograft recipients, which increases the risk of CMV pneumonia by twofold or more [2]. Whether therapy for GVHD further increases this risk is less clear. In multivariate analyses, CMV pneumonia is more common among older patients

Correspondence: S.W. Crawford, Fred Hutchinson Cancer Research Center, University of Washington, Seattle, Washington, USA. and possibly among patients receiving more intensive conditioning regimens or receiving methotrexate prophylaxis for GVHD. As a corollary to the increased risk associated with acute GVHD, patients not subject to GVHD have a lower incidence of pneumonia. Thus, CMV pneumonia is less common among recipients of autologous transplants (about 4\%) and exceedingly uncommon among recipients of twin marrow $[7,8]$.

CMV pneumonia was previously fatal in over $85 \%$ of affected marrow recipients. Multiple experimental treatment modalities were unsuccessful in altering outcome. Several centres have reported favourable responses to combination therapy with ganciclovir and high-titre antiCMV immunoglobulin [9-11]. Various treatment regimens have been used successfully, usually initially involving administration of ganciclovir $2.5 \mathrm{mg} \cdot \mathrm{kg}^{-1}$ t.i.d. for at least 2 weeks, together with CMV immunoglobulin 400-500 $\mathrm{mg} \cdot \mathrm{kg}^{-1} 3-5$ times weekly for 2-3 weeks. In some series, continued therapy with lower dose ganciclovir and CMV immunoglobulin for a period of several weeks after successful therapy has been suggested in order to avoid early relapse.

Thus, CMV pneumonia has been of primary concern as a cause of morbidity and mortality among marrow recipients. However, up to $12 \%$ of patients develop diffuse pneumonia in which no infection can be detected. The name "idiopathic pneumonia syndrome" has recently been applied to describe the clinical presentation of these apparently noninfectious processes [12]. Concern that undetected viral infection may account for a proportion of these idiopathic pneumonias has persisted in the marrow transplant community. As reported in this issue of the Journal, BARBERÁ et al. [1] from Barcelona examined the necropsy lung tissue of 19 marrow transplant recipients, who displayed histology of diffuse alveolar damage (DAD), for evidence of viral infection. These cases had no characteristic histological features suggesting viral pneumonia, such as Cowdry type A intracytoplasmic inclusion bodies, other than the presence of DAD. In situ hybridization with biotinylated nucleic acid probes and immunohistochemistry with antibodies to CMV, HSV, Epstein Barr virus (EBV) and adenovirus were performed and detected CMV deoxyribonucleic acid (DNA) and/or protein antigen in six cases. Notably, and consistent with the epidemiology of the infection, only necropsy tissue from patients with a history of allogeneic marrow transplant and acute GVHD were positive for CMV. Despite the fact that 13 of these patients had undergone bronchoalveolar lavage (BAL), CMV infection had been suspected in only a single case (on the basis of serological changes). Necropsy viral studies from cases with normal lung histology were negative. 
These authors are not the first to confirm that CMV infection can be demonstrated in lung tissue that lacks the pathognomonic characteristics of CMV pneumonia [13]. The conclusion that CMV infection is more common than recognized by conventional histopathology alone is clearly correct. More importantly, the authors conclude that "the incorporation of sensitive techniques" may help in assessing the presence of CMV infection. This is key, especially in the evaluation of BAL fluid. Studies both by Emanuel et al. [14] and CRAWFORD et al. [15] confirm that cytopathic changes in BAL fluid are significantly less sensitive for the detection of CMV infection than immunofluorescent monoclonal anitbody staining or rapid centrifugation culture. Cytology alone detects no more than $29 \%$ of infected cases, whereas centrifugation culture approaches the sensitivity of standard "tube" culture.

Unfortunately, the Barcelona investigators used none of these more sensitive techniques in the evaluation of the BAL fluids. Therefore, it can be argued that the CMV infections noted at necropsy were less "previously undetected" than "previously incompletely evaluated". The need to incorporate sensitive diagnostic techniques for the detection of viral infection in the routine evaluation of BAL fluid was recognized by the participants in the National Institutes of Health Workshop on Idiopathic Pneumonia [12]. The categorization of a diffuse pneumonia after marrow transplantation as "idiopathic pneumonia syndrome" requires not only radiographic and physiological evidence of lung inflammation, but also absence of active lower respiratory tract infection documented by: negative BAL; lung biopsy or autopsy with examination of stains and cultures for bacteria, fungi and viruses, including CMV centrifugation culture; cytology for viral inclusions and Pneumocystis carinii; and immunofluorescence monoclonal antibody staining for CMV, respiratory syncytial virus, influenza virus, parainfluenza virus and adenovirus. The study by BARBERÁ et al. [1] in this issue of the Journal demonstrates the potential clinical importance of a complete examination of BAL or lung biopsy tissue.

That being said, there is reason to question the relevance of necropsy examination of lung tissue to the assessment of the pathogenesis of diffuse pneumonia after marrow transplantation. We reviewed 41 open-lung biopsies performed at the Fred Hutchinson Cancer Research Center in Seattle between 1983 and 1988 that failed to reveal evidence of infection after exhaustive evaluation [16]. Either CMV or HSV was cultured from the lungs of 8 of 13 patients who underwent necropsy or second biopsy. Given the demonstrated high sensitivity of centrifugation culture and immunofluorescence monoclonal antibody staining for detection of viruses, it is highly probable that secondary (or subsequent) viral infection is common before death. Also, Aspergillus spp. were frequent at necropsy. It is more difficult to determine whether these fungi represent secondary infection or "missed" diagnoses because of the notorious insensitivity of the diagnostic techniques presently available to detect fungi.

Thus, detection of virus after death may not necessarily imply causation of the pneumonia. Interestingly, in a more recent review of all cases between 1989 and 1992 satisfying the criteria of idiopathic pneumonia syndrome, no viral infections were detected at necropsy, but fungi continued to be prevalent [17]. This decline in "secondary" viral infection may be related to improved surveillance and prompt treatment with antiviral agents.

We have also observed that the histopathological pattern of lung injury frequently changes between the onset of a diffuse idiopathic pneumonia and necropsy. In our experience, at the onset of diffuse idiopathic pneumonia, lung biopsy demonstrates a mononuclear interstitial infiltrate with varying degrees of fibrosis in over $50 \%$ of cases, and DAD in approximately one-third. However, at necropsy, the majority of cases display lung histology consistent with DAD, including many of the cases previously noted to have mononuclear interstitial infiltrate. These findings suggest that additional lung injury leading to DAD is common among marrow recipients dying with idiopathic pneumonia. Such a process may explain the predominance of DAD histology found at necropsy by BARBERÁ et al. [1]. Thus, similar to viral infection, the presence of DAD at necropsy may be unrelated to the pathogenesis of the original diffuse pneumonia. Investigators should be cautious in ascribing clinical or aetiological significance to the histopathological appearance of the lung at necropsy.

Where does this leave us in the evaluation of CMV pneumonia? Whilst the technology for detecting pulmonary infection has improved, other advances have led to a decline in the incidence of the problem. Efforts to prevent CMV pneumonia have been directed primarily at preventing CMV infection and pre-emptively treating patients at highest risk of pneumonia. High-dose acyclovir delays reactivation of latent virus and reduces the probability of CMV pneumonia by approximately $50 \%$ in seropositive allogeneic but not autologous transplant recipients [18, 19].

CMV pneumonia can be prevented in virtually all cases with the prophylactic administration of ganciclovir to all seropositive recipients. This approach, however, did not lead to improved overall survival due to an increase in sepsis related to the ganciclovir-induced neutropenia [20]. An additional theoretical concern with this approach is a delay in re-establishing CMV-specific CTL and, thus, the increased risk for CMV pneumonia at a later time. The majority of seropositive patients who are at the highest risk of developing CMV pneumonia can be prospectively identified by routine cultures of body fluids. Patients with positive blood, throat, urine or bronchoalveolar lavage cultures have a significantly increased probability of developing CMV pneumonia. Treatment of patients at the time of viral excretion significantly decreases the incidence of CMV pneumonia and improves survival, but $30 \%$ of marrow recipients develop CMV pneumonia without recognized excretion and are missed by this approach [21-23]. Detection of CMV antigens in blood leucocytes (using peroxidase-labelled monoclonal antibodies) or CMV DNA in plasma or blood leucocytes (using polymerase chain reaction) may be sensitive, specific techniques to identify patients at highest risk for CMV pneumonia [24-26]. Studies suggest the negative predictive value of such testing approaches to be $>95 \%$. Prospective use of these technologies after allogeneic transplantation may permit pre-emptive treatment with ganciclovir and the elimination of CMV pneumonia.

Although prophylactic and early treatment strategies are causing a significant decline in CMV pneumonia, the 
spectre of other viruses (such as human herpesvirus-6 (HHV-6)) as contributors to diffuse "idiopathic" lung injury in immunosuppressed patients continues [27]. Detailed evaluations of bronchoalveolar lavage and lung tissue using sensitive probes, such as those employed by BARBERÁ et al. [1], will continue to play an important role in assessing causation. Most importantly, sensitive and specific diagnostic techniques should continue to be applied to the routine clinical evaluation of pneumonia after marrow transplantation to detect the otherwise "occult" viral infection.

\section{References}

1. Barberá JA, et al. Undetected viral infection in diffuse alveolar damage associated with bone marrow transplantation. Eur Respir J 1996; 9: 1195-1200.

2. Meyers JD, Flournoy N, Thomas ED. Nonbacterial pneumonia after allogeneic marrow transplantation: a review of ten years experience. Rev Infect Dis 1982; 4: 1119-1132.

3. Crawford SW, Hackman RC, Clark JG. Open lung biopsy diagnosis of diffuse pulmonary infiltrates after marrow transplantation. Chest 1988; 94: 949-953.

4. Winston DJ, Huang ES, Miller MJ, et al. Molecular epidemiology of cytomegalovirus infections associated with bone marrow transplantation. Ann Intern Med 1985; 102: 16-20.

5. Riddell SR. Pathogenesis of cytomegalovirus pneumonia in immunocompromised hosts. Semin Respir Infect 1995; 10: 199-208.

6. Bowden RA, Sayers M, Flournoy N, et al. Cytomegalovirus immune globulin and seronegative blood products to prevent primary cytomegalovirus infection after marrow transplantation. N Engl J Med 1986; 314: 1006-1010.

7. Reusser P, Riddell SR, Meyers JD, Greenburg PD. Cytotoxic T-lymphocyte response to cytomegalovirus after human allogeneic bone marrow transplantation: pattern of recovery and correlation with cytomegalovirus infection and disease. Blood 1991; 78: 1373-1380.

8. Ljungman P, Biron P, Bosi A, et al. Cytomegalovirus interstitial pneumonia in autologous bone marrow transplant recipients: Infectious Disease Working Party of the European Group for Bone Marrow Transplantation. Bone Marrow Transplant 1994; 13: 209-212.

9. Emanuel D, Cunningham I, Jules-Elysee K, et al. Cytomegalovirus pneumonia after bone marrow transplantation successfully treated with the combination of ganciclovir and high-dose intravenous immune globulin. Ann Intern Med 1988; 109: 777-782.

10. Reed EC, Bowden RA, Dandliker PS, Lilleby KE, Meyers JD. Treatment of cytomegalovirus pneumonia with ganciclovir and intravenous cytomegalovirus immunoglobulin in patients with bone marrow transplants. Ann Intern Med 1988; 109: 783-788.

11. Schmidt GM, Kovacs A, Zaia JA, et al. Ganciclovir/ immunoglobulin combination therapy for the treatment of human cytomegalovirus-associated interstitial pneumonia in bone marrow allograft recipients. Transplantation 1988; 46: 905-907.

12. Clark JG, Hansen JA, Hertz MI, Parkman R, Jensen L, Peavy H. NHLBI Workshop Summary. Idiopathic pneumonia syndrome following bone marrow transplantation. Am Rev Respir Dis 1992; 147: 1601-1606.
13. Myerson D, Hackman RC, Nelson JA, Ward DC, McDougall JK. Widespread presence of histologically occult cytomegalovirus. Hum Pathol 1984; 15: 430-439.

14. Emanuel D, Peppard J, Stover D, Gold J, Armstrong D, Hammerling U. Rapid immunodiagnosis of cytomegalovirus pneumonia by bronchoalveolar lavage using human and murine monoclonal antibodies. Ann Intern Med 1986; 104: 476-481.

15. Crawford SW, Bowden RA, Hackman RC, Gleaves CA, Meyers JD, Clark JG. Rapid detection of cytomegalovirus pulmonary infection by bronchoalveolar lavage and centrifugation culture. Ann Intern Med 1988; 108: 180185.

16. Crawford SW, Hackman RC. Clinical course of idiopathic pneumonia after marrow transplantation. Am Rev Respir Dis 1993; 147: 1393-1400.

17. Kantrow SP, Hackman RC, Boeckh M, Myerson D, Crawford SW. Idiopathic pneumonia syndrome after marrow transplantation: the changing spectrum of lung injury. Am J Respir Crit Care Med (in press).

18. Meyers JD, Reed EC, Shepp DH, et al. Acyclovir for prevention of cytomegalovirus infection and disease after allogeneic marrow transplantation. N Engl J Med 1988; 318: 70-75.

19. Boeckh M, Gooley TA, Reusser P, Buckner CD, Bowden RA. Failure of high-dose acyclovir to prevent cytomegalovirus disease after autologous marrow transplantation. J Infect Dis 1995; 172: 939-943.

20. Goodrich JM, Bowden RA, Fisher L, Keller C, Schoch G, Meyers JD. Ganciclovir prophylaxis to prevent cytomegalovirus disease after allogeneic marrow transplant. Ann Intern Med 1993; 118: 173-178.

21. Goodrich JM, Mori M, Gleaves CA, et al. Early treatment with ganciclovir to prevent cytomegalovirus disease after allogeneic bone marrow transplantation. $N$ Engl J Med 1991; 325: 1601-1607.

22. Goodrich JM, Reed EC, Mori M, et al. Clinical features and analysis of risk factors for invasive candidal infection after marrow transplantation. J Infect Dis 1991; 164: 731-740.

23. Schmidt GM, Horak DA, Niland JC, Duncan SR, Forman SJ, Zaia JA. A randomized, controlled trial of prophylactic ganciclovir for cytomegalovirus pulmonary infection in recipients of allogeneic bone marrow transplantation. N Engl J Med 1991; 324: 1005-1011.

24. Boeckh M, Myerson D, Bowden RA. Early detection and treatment of cytomegalovirus infections in marrow transplant patients: methodological aspects and implications for therapeutic interventions. Bone Marrow Transplantation 1994; 14 (Suppl 4): S66-S70.

25. Einsele H, Steidle M, Vallbracht A, Saal JG, Ehninger G, Müller CA. Early occurrence of human cytomegalovirus infection after bone marrow transplantation as demonstrated by the polymerase chain reaction technique. Blood 1991; 77: 1104-1110.

26. Jiwa NM, van Gemert GW, Raap AK, et al. Rapid detection of human cytomegalovirus DNA in peripheral blood leukocytes of viremic transplant recipients by the polymerase chain reaction. Transplantation 1989; 48: $27-$ 76.

27. Cone RW, Hackman RC, Huang M-LW, et al. Human herpesvirus- 6 in lung tissue from patients with pneumonitis after bone marrow transplantation. $N$ Engl J Med 1993; 329: 156-161. 